\title{
RESEÑA: BUIO. DACIA MARAINI ${ }^{1}$
}

\author{
Begoña González Rodríguez ${ }^{2}$
}

\section{Dacia Maraini. Buio. Milano: BUR Rizzoli Contemporanea, 2018. ISBN: 978-88- 17-25182-2.}

La primera edición de Buio tiene lugar hace 21 años, en 1999, de manos de la editorial Rizzoli, de Milán. A esta le siguieron 12 ediciones más hasta la actual de 2018, publicada por BUR Contemporanea.

Buio forma parte de la larga lista de obras narrativas de la escritora italiana Dacia Maraini, siendo su primera publicación La Vacanza, en 1962, y la última, en 2018, Corpo felice. Storie di donne, rivoluzioni e un figlio che se ne va. Igualmente, Buio se enmarca dentro de las novelas a las que la Maraini ha dedicado como tema principal la violencia contra las mujeres y las niñas y niños. La escritora ha dedicado muchas obras, tanto narrativa como teatro, poesía o ensayo a denunciar mediante la ficción esa violencia que, de forma frecuente, sufren las mujeres en todo el mundo. Junto a Buio, por continuar en la línea de la narrativa, algunas obras que han seguido dicha temática son Isolina (1985), Voci (1994), La lunga vita di Marianna Ucrìa (1990), Bagheria (2004) o Amore rubato (2013).

A través de la escritura, Maraini deja presente su sensibilidad y empatía ante infinidad de atropellos hacia las personas, en particular las más vulnerables. Esas

\footnotetext{
${ }^{1}$ Fecha de recepción: 08/10/2019.

Fecha de aceptación: 08/10/2019.

${ }^{2}$ Estudiante de doctorado, Departamento de Filologías Integradas, Universidad de Sevilla, España; gr2be@hotmail.com.
} 
injusticias son atemporales, ya que es posible leer textos suyos escritos en los noventa que, perfectamente, podrían haber sucedido ayer, pues sus denuncias sociales siguen latentes. Una de las temáticas que se ha convertido en una denuncia constante en sus escritos es la vulnerabilidad de la condición femenina y la cruda realidad a la que se enfrentan las mujeres, principalmente su exposición a diversos actos violentos. Como refleja Solorza en una entrevista con Dacia Maraini, la italiana sostiene que "No existe una conexión directa entre el relato y el poder cambiar el mundo. Pero la escritura no puede ir separada del conocimiento y el conocimiento ayuda a entender mejor el mundo, y entender el mundo quiere decir poder cambiarlo" (Solorza 2015: 2).

Lejos de relatos románticos, propios de los cuentos de hadas, Dacia se sumerge en los aspectos más profundos, oscuros y complejos de la problemática que quiere hacer visible, para, después, darle forma narrativa siguiendo su toque personal (Maraini 2018: 55). Este procedimiento será visible en Buio.

Aunque la obra fue publicada a finales de los años noventa, resultaría difícil atribuirle un contexto histórico concreto, puesto que las realidades abordadas podrían suceder en cualquier momento sin tener que asociarlas a una época concreta. No obstante, está claro que las sentimos contemporáneas, ya que en la actualidad se busca visibilizar las tramas que narra Maraini en el libro. No existe el miedo a que salgan a la luz y sean cuestionadas, ni, mucho menos, a que se pueda pensar en relatos excepcionales, irreales o imposibles, fruto de la narrativa de ficción.

La obra está compuesta por 12 relatos diferentes y sin relación entre ellos. El principal nexo que los une es que en todos ellos reina la violencia. La mayoría de los personajes son niñas y niños que sufren algún tipo de violencia y en los que los verdugos son diversos, desde individuos sin relación con sus víctimas a otros que 
comparten vínculos estrechos y familiares. Conviene hacer especial alusión al papel de Adele Sòfia, la comisaria omnipresente en todos los relatos en los que es necesaria la intervención policial, un personaje al que Maraini también ha recurrido en su novela Voci. Otra característica común en las historias tiene que ver con el nombre de la obra, "oscuridad" en español, pues resume una característica presente en todas ellas. En todos los relatos no encontramos esa oscuridad en su sentido más amplio, desde el literal al figurado. Narraciones siniestras que tienen lugar en espacios inhóspitos, lúgubres o que se producen en la noche. Relatos que están relacionados con los aspectos más oscuros de un individuo. Personajes atrapados en historias truculentas y, de nuevo, oscuras, sin luz, sin vida, apagadas y con pocas esperanzas de alumbrarse.

Con el relato "Il Bambino Grammofono e l'Uomo Piccione" inicia la obra, que nos presenta un caso de pedofilia. Un adulto juega con la inocencia e ingenuidad de un niño que deposita su confianza en él. Esa es el arma que aprovechan los pedófilos para cumplir sus enfermos deseos. El hombre del relato, que trabaja como asistente social con niños con discapacidad, se aprovecha de un niño que se encuentra en la calle y empieza a ganarse su confianza, conduciéndolo hasta un trágico final.

En el siguiente relato "Viollca la bambina albanese", la familia de Viollca, una niña albanesa, la "vende" a una mafia italiana que le promete una vida mejor y un salario mensual para la familia. Una vez en Italia, la niña se ve obligada, por medio de amenazas y violencia, a mantener relaciones sexuales pactadas. La denuncia principal del relato tiene que ver con la trata de personas y la prostitución infantil; siguiendo la frecuente costumbre de oír hablar de "las esclavas del este" para referirse a la prostitución de mujeres o niñas. Como relata Vullyami (2005), en países como Albania la prostitución de menores se ha convertido en un negocio lucrativo que se sitúa por delante del tráfico de drogas o armas; así, muchas niñas se embarcan en una aventura 
que las conduce a la denigración y a la privación de libertad. En el relato de Maraini, los verdugos de Viollca son descubiertos y el sufrimiento de la niña no se prolonga en el tiempo, pero el daño ya se ha hecho y la familia se desentiende de haber consentido esa aventura para la niña.

El relato "Le galline di suor Attanasia" tiene como protagonista a una joven monja de un convento cristiano de Mali. El lugar es saqueado y muchas monjas son asesinadas o violadas. Esto es lo que le sucede a la protagonista. La denuncia principal del relato podemos asociarla con la violencia que sufren muchas mujeres en países con constantes guerras civiles, donde quienes sufren las peores consecuencias son las mujeres y las niñas y niños. No obstante, la historia busca también poner de manifiesto la reacción de la Iglesia ante esta situación. La protagonista, embarazada tras la violación, se convierte en un escándalo para el convento. Unos defienden que debe abortar, mientras que otros le aconsejan que su embarazo llegue a término pero en secreto. Así sucede, pero nunca se piensa en los sentimientos que pueda experimentar Attanasia, quien, conforme avanza el relato, experimenta delirios que a nadie parecen preocuparle y cuyo final no es agradable.

"Macaca", el título del siguiente relato, proviene del apodo que un hombre pone a su esposa, despojándola de identidad y comparándola con un animal. La mujer vive en una constante humillación sexual, siendo obligada por su esposo a realizar diferentes prácticas delante de sus amigos, con el fin de satisfacer sus deseos. Las humillaciones vienen acompañadas de maltrato físico cuando la mujer no cumple con las exigencias del hombre. Maraini quiere evidenciar la subordinación femenina, mostrando cómo, en esta historia, la protagonista, al igual que muchas mujeres en la vida real, es un objeto de satisfacción, algo que mostrar y a quien puede manejarse según la voluntad masculina. 
En el relato "Alicetta", Dacia Maraini nos cuenta la historia de una niña que a causa de su esquizofrenia es tratada en una clínica especializada. Lejos de procurarle un bienestar, la niña muere prematuramente a causa de una sobredosis de sedantes, que los enfermeros que se ocupaban de cuidarla utilizaban para poder abusar sexualmente de ella. La escritora muestra que nos sentimos desprotegidas en cualquier lugar, incluso en organismos sanitarios, donde se presupone un interés por el cuidado de las personas.

En "Muri di notte", una mujer responde a un interrogatorio policial, tras haber matado a su marido cuando este intentaba apuñalarla. A pesar de la gravedad de los hechos, la mujer relata una serie de situaciones en las que describe la relación con su esposo como una especie de simbiosis entre ambos, en la que ella estaba siempre a su servicio. La protagonista defiende la actitud posesiva de su marido e, incluso, justifica el intento de asesinato como un acto de amor: "Non potrebbe avere tentato di uccidermi per troppo amore?” (Maraini 2018: 93). La escritora está haciendo una denuncia de la condición de subordinación femenina que ha sido transmitida a lo largo de los siglos. Una condición que ha hecho que se ensalzara la figura masculina mientras que la femenina queda relegada a un segundo plano.

En el relato "Ha undici anni, si chiama Tano", se narra la historia de Tano, un niño que sufre abuso sexual por parte de su padre, pero no solo él, sino también sus hermanos. Tano denuncia ante la justicia tales atrocidades, pero siempre le ignoran. Sin embargo, sus años de denuncias empiezan a tenerse en cuenta cuando su hermano pequeño aparece muerto y su padre resulta ser el culpable. Maraini ha escrito muchas veces acerca de la violencia sexual dentro del entorno familiar, denunciando en particular el abuso sexual a niñas dentro de la propia familia. Algo que Maraini ya había comentado en otras obras suyas, como, por ejemplo, Bagheria (2004), donde el contexto histórico se remonta a los años 30-40, cuando los abusos de carácter sexual 
dentro de la familia por parte del progenitor eran algo frecuente, normalizado y aceptado en el círculo familiar. En algunos casos era un tabú, mientras que en otros era un secreto que nadie se atrevía a desvelar, y, mucho menos, a denunciar.

En "Un numero sul braccio", la protagonista del relato, Mara Grado, ha sobrevivido al Holocausto. Años más tarde, en Latinoamérica, reconoce a uno de los hombres que controlaban el campo de concentración en que ella había estado. Ese hombre, que ahora tiene una nueva identidad y una nueva vida, reconoce, cuando Mara se enfrenta a él, un oscuro pasado del cual no se arrepiente.

En el relato "Oggi è oggi è oggi", una periodista investiga el caso de Marinella, una joven que viajaba a Roma para visitar el Vaticano; objetivo que no llega a cumplir porque es asesinada en cuanto llega a la capital. La joven confía en un hombre por quien, supuestamente, sintió atracción y mantiene una relación sexual que termina con su asesinato. Una ejecución que el asesino defiende como un acto de amor: "l'ho amata, anche se per poco. Se non l'avessi amata non avrei sentito il bisogno di compiere fino in fondo il mio gesto d'amore. La morte sancisce una ripetizione che va vanti in eterno" (Maraini, 2018: 172). La escritora expone un suceso bastante frecuente, pues hay muchos casos recientes en los que mujeres que acaban de conocer a alguien con quien deciden pasar un rato al final desaparecen o aparecen muertas.

La historia narrada en "Chi ha uccisso Paolo Gentile" es un ejemplo de intolerancia hacia la orientación sexual. Paolo Gentile mantenía una relación con una mujer transexual; lo cual no era aceptado por su familia, especialmente por su padre. Una discusión hizo que acabara estrangulándolo: "lo preferivo morto che snaturato" (Maraini 2018: 184). Muchas familias no aceptan las orientaciones de sus hijos; algo impuesto por la sociedad heteronormativa que condena el resto de sexualidades. 
En el relato "Il pastore Ahmed e le tre ragazze nel bosco", tres chicas son torturadas, violadas y dos de ellas asesinadas, mientras hacían una excusión por el bosque. Un pastor es testigo de esa escena dantesca. El hombre, no hizo nada, salvo quedarse atónito, pues el verdugo era un terrateniente para el cual trabajaba. El miedo le hizo callar, e incluso poner en juego su inocencia. Una vez más, las jóvenes están expuestas a la violencia proveniente de individuos desconocidos que eligen a sus víctimas al azar.

En el último relato, "Ombre”, Maraini denuncia la desposesión de las niñas de su propio cuerpo, que pasa a serles ajeno y a estar a disposición de otras personas. En este caso, una abuela acompaña a su nieta a un encuentro sexual con un señor mayor que la anciana, previamente, había pactado económicamente. Afortunadamente para la niña del relato, la relación no llegó a producirse, sin embargo, es un fenómeno frecuente que, en muchas ocasiones, acaba llevándose a cabo. Muchas familias, como sucedía con la historia de Viollca, participan en la explotación sexual infantil, comercializando la inocencia de sus hijas, consideradas objetos de placer que los hombres pueden utilizar a su antojo y por quienes están dispuestos a pagar grandes sumas de dinero con el fin de satisfacer un enfermo deseo.

Está claro que Buio invita al lector a reflexionar y establecer paralelismos con situaciones que se puedan identificar con la realidad; fenómenos que le resulten familiares y problemáticas que se repiten en cualquier época y sociedad. Las historias de Maraini no suelen tener finales felices. Todos los protagonistas sufren algún tipo de violencia que, si bien es cierto que no en todos los casos termina con sus vidas, sí que les deja una marca considerable. Así es la realidad, que tanto persigue mostrar la escritora, en la que, desgraciadamente, no siempre hay un final agradable. Por ello, sintiendo un fuerte compromiso social y aprovechando la influencia que la literatura 
puede ejercer en un gran número de personas, Maraini opta por reflejarla sin velos ni tapujos en sus escritos, consciente de que, muchas veces, el mostrar una cruda realidad hace que se genere una reflexión que puede ayudar a cambiar el estado las cosas.

\section{Referencias Bibliográficas}

Maraini, Dacia. 2018. Amata scrittura. Milano: BUR Contemporanea. .2018. Buio. Milano: BUR Contemporanea.

Solorza, Paola Susana. 2015. "Entrevista a Dacia Maraini: Entre la escritura y el activismo: Historias de una narradora inconformista". Argus-a. Artes y Humanidades, IV (17).

Vullyami, Ed. 2005. "Las esclavas del Este". El País (30 de enero de 2005). https://elpais.com/diario/2005/01/30/eps/1107070008_850215.html [30/01/2005] 